\section{Response to : 'Interleukin-4 as a emerging target for IgG4-related disease' by Akiyama et al}

We thank Akiyama et al, for their kind words regarding our manuscript. ${ }^{1}$ We agree that IgG4-related disease (IgG4-RD) relapse frequently occurs in patients tapering glucocorticoids, and we wanted to offer a novel solution to our patient to potentially mitigate or all together avoid this. As communicated in our previous correspondence response $\mathrm{e}^{2}$ it has actually come to our attention post-publication (December $29^{\text {th }}, 2019$ ) that the patient noted in our report never took a dose of prednisone that was prescribed to him due to undisclosed non-compliance. Therefore, the remission of IgG4-RD can be completely attributed to dupilumab treatment. We are happy to report our findings and hope that our report will propel this treatment to be studied further for the treatment of this disease which otherwise, as you mentioned, is poorly controlled by glucocorticoids especially when tapering, ${ }^{3}$ and when other agents such as chemotherapeutic immunosuppressants come with profound adverse effects. ${ }^{4}$ Although this disease has a low prevalence, so low that it is actually unknown due to being underrecognized or underreported, ${ }^{1}$ it does have a significant mortality rate, showing the importance of developing novel therapies to control this disease. It is our conceptual understanding that some IgG4-RD is an extreme example of unabated type II inflammation, which we have seen similar pathology in chronic spontaneous urticaria. ${ }^{5}$

We thank Akiyama et al for their interest in the exclusion of ANCA-associated vasculitides, including granulomatosis with polyangiitis (GPA), microscopic polyangiitis (MPA), and eosinophilic granulomatosis with polyangiitis (EGPA) in the differential diagnosis of this patient. When the patient originally presented, atypical EGPA was part of the differential diagnosis due to the reasons Akiyama et al stated and was excluded before the diagnosis of IgG4-RD was made. This was a consideration given his lower airway symptoms. The suspicion of small vessel vasculitis diminished due to the fact that the patient did not have a fever, nor elevated neutrophil counts nor elevated serum C-reactive protein levels. Regarding the prostate biopsy, there was no neutrophilic infiltration, granulomatous formation, necrotizing vasculitis, or multinucleated giant cells. ANCA testing was negative; however, it should be noted that many patients with ANCA-associated vasculitides actually do not test positive for P-ANCA and C-ANCA. ${ }^{6}$ Although IgG4-RD and ANCA-associated vasculitides can overlap in clinical presentations, we further believe it is unlikely that the patient had an ANCA-associated vasculitis such as EGPA because dupilumab can actually raise eosinophil levels due to changes in VCAM-1 expression and eosinophilia is central to the pathophysiology of EGPA. ${ }^{7}$ We observed that as eosinophil levels became raised from the baseline level of $1.4 \times 10^{9}$ cells $/ \mathrm{L}$ to $2.0 \times 10^{9}$ cells $/ \mathrm{L}$ (normal range $0-0.5 \times 10^{9}$ cells/L) at 4 months into dupilumab treatment likely due to the aforementioned indirect cell trafficking changes from dupilumab. It was noted that the patient's symptoms continued to improve in spite of the increased eosinophilia.

To address Akiyama et al.'s second question, we believe the eye swelling was most likely caused by atopic dermatitis as this was a concurrent condition the patient presented with; however, it is possible this was a manifestation of IgG4-RD as this cannot be ruled out completely. His eye swelling completely resolved at 3 months post-dupilumab treatment. With regards to parotitis, this manifestation was resolved at 12 months post dupilumab treatment, as determined by physical examination as MRI was only done of the lumbar plexus region. ${ }^{1}$
In regard to Akiyama's third point, the original MRI of the pelvis (pictured as figure $1 \mathrm{~A}$ in our original paper) ${ }^{4}$ was ordered by a gastroenterologist in order to rule out pathologies associated with normocytic anaemia which the patient was being worked up for. When this MRI revealed profound retroperitoneal and genitourinary thickening, the radiologist suggested follow-up with a urologist whom recommended the prostate biopsy to rule out malignancy and also to obtain a tissue diagnosis for suspected IgG4-RD as the patient had extensive retroperitoneal thickening and elevated IgG4 levels. The prostate was asymptotic at the time this fibrosis was found and was an incidental finding in the work-up for normocytic anaemia. Once malignancy was ruled out by the biopsy, urology deemed the case to most likely be IgG4-RD and therefore referred the patient to rheumatology.

Once again, we would like to thank Akiyama et al for their interest in our paper and providing their questions through correspondence. We believe dupilumab to be a promising monotherapy and/or addon for IgG4-RD and look forward it being studied further through randomised control trials to investigate large-scale safety and efficacy of this novel treatment.

\section{Rachel S Simpson $\bullet^{\circ}$, Jason K Lee}

Toronto Allergists, Toronto, Ontario, Canada

Correspondence to Ms Rachel S Simpson, Toronto Allergists, Toronto, ON M5G 1E2, Canada; rachel.simpson@queensu.ca

\section{Handling editor Josef S Smolen}

Contributors RSS undertook the primary duties in writing the manuscript. JKL oversaw the manuscript writing and edited the manuscript.

Funding The authors have not declared a specific grant for this research from any funding agency in the public, commercial or not-for-profit sectors.

Competing interests JKL reports receiving research grants, clinical research trial funding and speaker fees from Novartis, Sano, Regeneron, Sano Genzyme, Astrazeneca, Genentech, Roche and GlaxoSmithKline as well as personal fees from ALK, grants and personal fees from Aralez, and grants and personal fees from Pediapharm. RSS reports having nothing to disclose.

Patient consent for publication Obtained.

Provenance and peer review Commissioned; internally peer reviewed. (C) Author(s) (or their employer(s)) 2020. No commercial re-use. See rights and permissions. Published by BMJ.

\section{Check for updates}

To cite Simpson RS, Lee JK. Ann Rheum Dis Epub ahead of print: [please include Day Month Year]. doi:10.1136/annrheumdis-2020-216977

Received 27 January 2020

Accepted 28 January 2020

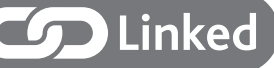

http://dx.doi.org/10.1136/annrheumdis-2020-216961

Ann Rheum Dis 2020;0:1-2. doi:10.1136/annrheumdis-2020-216977

\section{ORCID iD}

Rachel S Simpson http://orcid.org/0000-0003-1779-4049

\section{REFERENCES}

1 Akiyama M, Kaneko Y, Takeuchi T. Interleukin-4 as an emerging therapeutic target for IgG4-related disease. Ann Rheum Dis 2020. doi:10.1136/annrheumdis-2020-216961. [Epub ahead of print: 20 Jan 2020].

2 Simpson RS, Lee JK. Response to: 'Dupilumab as a potential steroid-sparing treatment for IgG4-related disease' by Della-Torre et al. Ann Rheum Dis 2020:1-2.

3 Sasaki T, Akiyama M, Kaneko Y, et al. Risk factors of relapse following glucocorticoid tapering in IgG4-related disease. Clin Exp Rheumatol 2018;112:186-9.

4 Simpson RS, Lau SKC, Lee JK. Dupilumab as a novel steroid-sparing treatment for lgG4related disease. Ann Rheum Dis 2019. doi:10.1136/annrheumdis-2019-216368. [Epub ahead of print: 19 Dec 2019]. 
5 Lee JK, Simpson RS. Dupilumab as a novel therapy for difficult to treat chronic spontaneous urticaria. J Allergy Clin Immunol 2019:7:1659-61.

6 Szczeklik W, Sokolowska B, Kuczia P, et al. Anca-Positive and ANCA-negative phenotypes of eosinophilic granulamatosis and polyangiitis (EGPA): outcome and long-term follow-up of 46 patients from a single Polish centre. La Presse Médicale 2013:42:699-700.

7 Plötz SG, Wiesender M, Todorova A, et al. What is new in atopic dermatitis/eczema? Expert Opin Emerg Drugs 2014;19:441-58. 